\title{
Quality Improvement of Steel Pipes Produced by Seam Welding with New Magneto-Dielectric Impeder
}

\author{
Miroslav Milićević ${ }^{1, *}$ and Zoran Radaković ${ }^{2}$ \\ ${ }^{1}$ Bul. Nemanjića 33/39, 18000 Niš, Serbia \& Montenegro \\ ${ }^{2}$ Department of Electrical Engineering, University of Belgrade, Bulevar Kralja Aleksandra 73, \\ 11000 Beograd, Serbia \& Montenegro
}

\begin{abstract}
The standard technology of steel pipe production is the high frequency (HF) inductive welding. A mechanically formed profile is introduced into an inductor. Inside the pipe, in the position of the inductor there is an impeder, whose function is to form a suitable distribution of the electromagnetic and temperature field. In previous paper of the authors, the new magneto-dielectric (MD) material for the impeder is proposed and results of extraordinary energy saving are shown.

This paper treats the aspect of the pipe quality, which represent the essential parameter in a production technology. The analyses were made for the widely spread ferrite impeder and for the proposed MD impeder. From this point of view, the MD impeder appeared to be advantageous material also. In addition to the standard mechanical tests of pipes quality, extensive chemical and physical analyses of the material in the weld, as well as in the basic section of the pipe, have been performed. The aim of the investigation was to explain the bad results in the standard flattening and hydrostatic testing of pipes produced using the ferrite impeder of TDK-IP1 type.

[doi:10.2320/matertrans.47.1464]
\end{abstract}

(Received November 28, 2005; Accepted March 7, 2006; Published June 15, 2006)

Keywords: high frequency inductive welding, ferrite, magneto-dielectric, impeder, testing of welding

\section{Introduction}

The idea of using the HF current for welding was suggested by Ulitovski in 1946. Since 1950, it has been introduced into the steel pipe production. The improvements of $\mathrm{HF}$ inductive welding were in a direction of development of the HF current generators and in a direction of forming the optimal distribution of the electromagnetic field. The development of the HF current generators is predominantly connected with the technological development of the components used in electric power generators. The development of field distribution embodies the development of the calculation methods, the improvement of the material of impeders and the experimental research on welding appliances. The precise calculation methods and experiments enable the improvements of the geometry, i.e. construction of the device. The theoretical bases for the calculation of the fields are given in the Ref. 1-3). Today there are several specialized software packages for the calculation of the electromagnetic and temperature field distribution (for example ELTA).

In the moment, the HF inductive welding is commonly used in the production of the pipes of diameter (17-220) $\mathrm{mm}$ and of thickness $(0.7-8) \mathrm{mm}$. The converters of power $(50$ 900) $\mathrm{kW}$, with frequency output (200-500) $\mathrm{kHz}$, made with tubular or transistor technology, are typically used.

The most important characteristic of HF inductive welding is the power consumption. There are different criteria for assessment of the power needed per unit product. They can be established on momentary values: the power output of the welding appliance converter $P[\mathrm{~kW}]$, the thickness of the steel strip $\delta[\mathrm{mm}]$ and the speed of the strip $v[\mathrm{~m} / \mathrm{min}]$. Such criteria are the specific power $\left[\mathrm{kW} /\left(\mathrm{mm}^{*}(\mathrm{~m} / \mathrm{min})\right)\right]$, defined as $P /\left(\delta^{*} v\right)$ in the Ref. 1$)$ or the heating coefficient $[\mathrm{kW} /(\mathrm{m} /$ min)], defined as $P / v$ in the Ref. 4). The authors in the

*Corresponding author, E-mail: Lavmiro@EUnet.yu
Ref. 5) have introduced, as a suitable criterion, the consumed power per ton of produced steel pipes $[\mathrm{kW} * \mathrm{~h} / \mathrm{ton}]$. The value of each of the above mentioned criteria functions depends on the diameter and the thickness of the welded pipe, as well as on the type of the steel, and especially on the type and construction of the impeder.

In the previous research, the authors was concerning the improvement of the impeder, introducing a new material. The results of the application of the MD impeder, that surpasses regarding power all ferrite impeders used so far, are presented in the Ref. 5).

In addition, the authors have proposed an improvement of the process of HF welding by applying a two-step process: the rims of the steel strip are heated to the temperature of $1250^{\circ} \mathrm{C}$ with the $\mathrm{HF}$ transistor generator, of frequency $350 \mathrm{kHz}$ and the further heating up to the welding temperature is performed with the middle-frequency generator $10 \mathrm{kHz}$. In such a way, a complete ferric oxide ( $\mathrm{FeO}, \mathrm{Fe}_{2} \mathrm{O}_{3}$ and $\mathrm{Fe}_{3} \mathrm{O}_{4}$, for example) is dissolved, while in the case of the standard procedures it can remain after the welding. The contributions in design of both transistor converters, through an analytical method for calculating the characteristic parameters of inverters, are exposed in the Ref. 6).

A further research of the authors was oriented to the quality of the weld and the methods of its testing. The results of this research represent the content of this paper. The analyses were performed on a widely-spread ferromagnetic impeder and on the proposed MD impeder.

\section{The construction of HF inductive Welding Appliance}

A detail of the final part of the appliance for HF inductive welding of steel pipes is shown in Fig. 1. The dimensions A, $\mathrm{B}$ and $\mathrm{C}$ (Fig. 1) are strongly influencing the characteristics of the welding process. Therefore, the establishing of their optimal values is an important task in the construction of the appliance. 


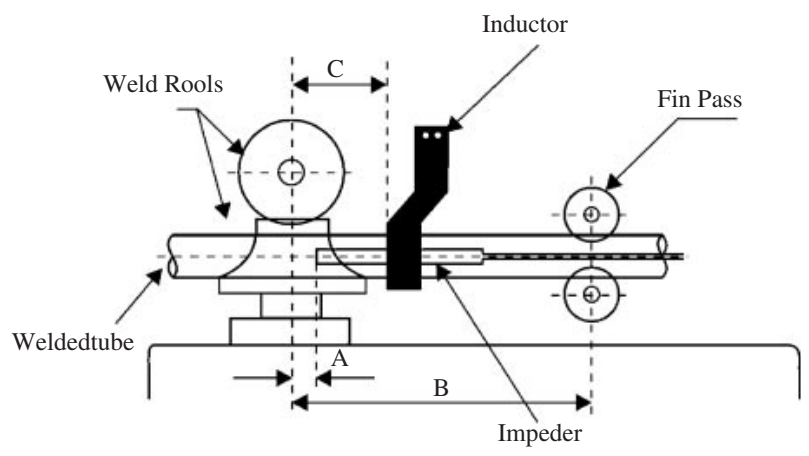

Fig. 1 The detail of the final part of the appliance for HF inductive welding.
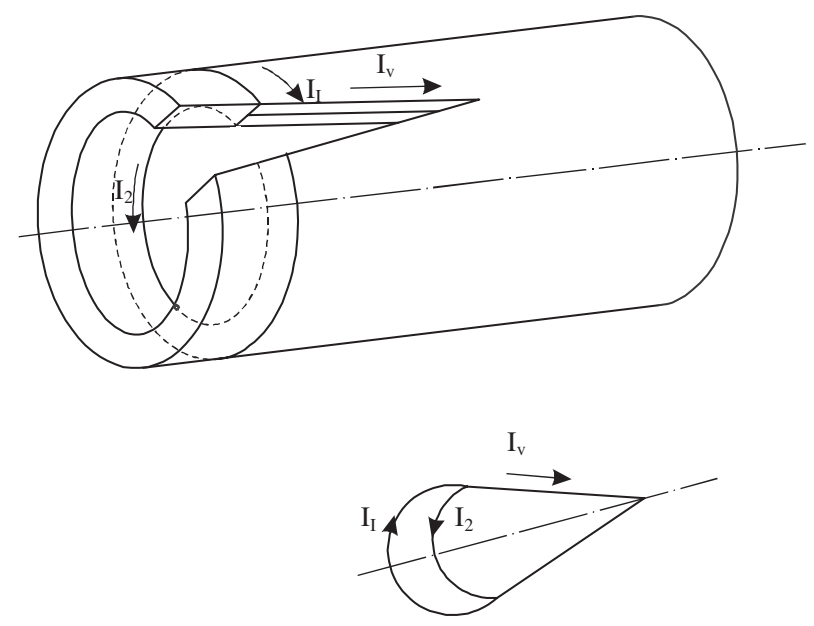

Fig. 2 The display of details of the pipe $\mathrm{V}$ loop with the division of characteristic currents.

The steel strip is shaped in the section of forming by cold deforming, with the line of contact of the strip rims adjusted symmetrically in respect to the weld rolls. A so-called "Vloop" is formed in the appliance, from the far end of the strip forming to the beginning of contact between the stripe rims. In order to realize the process of welding, it is necessary to heat up the parts of V-loop which are succeeding to the contact. Figure 2 shows the V-loop with its currents $\left(I_{\nu}\right)$ and the currents in the outer $\left(I_{1}\right)$ and inner $\left(I_{2}\right)$ circle arcs of the cross-section of the pipe. Due to the goal of heating, the only useful component of the current is $I_{v}$. The construction of the appliance and the characteristics of the materials used for the impeder should provide reduction of the $I_{1}$ and $I_{2}$ components, i.e. the reduction of "useless" heating up of the material outside the welding section. In addition, the construction should assure lower leakage flux and reactance, i.e. better power factor. By the higher power factor, the current of the HF electric source and consequent power losses are lower and the energy consumption per unity of pipe product is higher.

\section{The Methods of Testing the Quality of the Weld}

Two testing methods are commonly used for the control of quality in the production of steel pipes: mechanical testing on presses (so called flattening) and hydrostatic testing.
The hydro-testing is performed according to the standard in the Ref. 7), by testing all the pipes after the production cycle has been completed. The testing starts with flushing the interior of a pipe with the emulsion, continues with filling the pipe completely with the emulsion, throwing out the air, and the final raising of the inner pressure in the pipe up to 50 bars. The pipes are held under this testing pressure of 50 bars from 5 to $20 \mathrm{~s}$; the duration of the process depends on the thickness and diameter of the pipe.

The mechanical testing on presses by flattening is performed according to the standard in the Ref. 8), by testing randomly selected specimens of steel pipes during the process of production. A specimen of a pipe, the length of $(300-500) \mathrm{mm}$, is cut out from the pipe, the weld is placed laterally, and the flattening is performed by applying certain pressure, until the walls of the pipe are brought to approximately $1 / 3$ of the pipe's diameter.

The authors have introduced into the practice an additional test on presses on selected specimens, after the hydro-test has been performed. Frequently, the pipes have resisted the pressure on the hydro-test, but on the after-test on presses the weld was broken. The failures in the flattering were also a common result in the tests during the production cycle. The phenomena have prompted the authors to carry out researches regarding the quality of the weld.

The methods of mechanical, chemical and metallographic testing were applied both on the welding section and the basic section of the pipe. The characteristics of the material in these sections were compared with the characteristics of material of the incoming strip.

The mechanical test was testing the hardness by Rockwell's method, according to standard in the Ref. 9). The value of hardness is expressed in [HRC].

The chemical analyses were performed by applying an optic quant meter. A modern emission optical quant meter ARL-513, manufactured by Applied Research Laboratories in Austria was used.

The metallographic analyses were performed on the basis of the results that had been obtained by an electronic microscope with $(\times 200)$ magnification, as it is the usual practice in metallurgy of iron.

\section{The Results of the Application of the TDK and MD Impeders}

\subsection{The power consumption}

Detailed analyses for a ferrite impeder were conducted for the pipes welded by using a ferrite impeder of TDK-IP1 type. As a MD impeder, Fluxtrol A material was used.

The tests were performed on the pipes of diameter 26.9 $\mathrm{mm}$ and of thickness $2.5 \mathrm{~mm}$, and on the pipes of diameter $21.3 \mathrm{~mm}$ and of thickness $2.65 \mathrm{~mm}$. They had been selected for testing because they are massively produced and because, in the overall production program of FAHOP Company, problems occur most frequently on them. The pipes are made from easily welded steels with low carbon content.

On the basis of several years' practice of applying dozens of types of ferrite for welding it has been concluded that the lowest power consumption per speed of welding is achieved with the TDK ferrite. The optimal MD impeder turned to be 


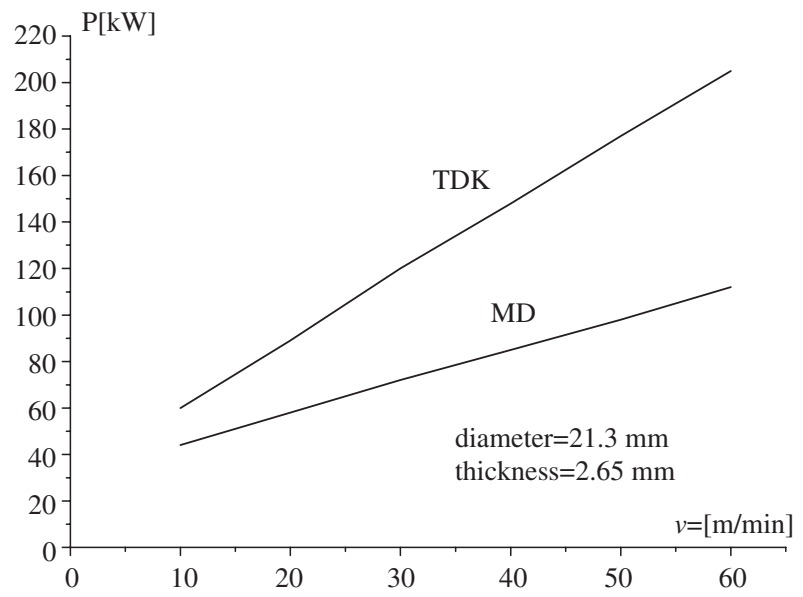

Fig. 3 The dependence of the consumed power from the speed of welding.

Fluxtrol A. The data for the pipe of diameter $21.3 \mathrm{~mm}$ are given in Fig. 3. The energy consumption is dominantly dependent on the value of magnetic permeability.

\subsection{The testing of hardness by Rockwell's method}

The first supplementary test to the standard mechanical flattening test and hydrostatic test, was the hardness measurement. It was performed in a number of points on the pipe weld of several specimens and on the basic section of the specimens, outside the weld.

The results for TDK and MD impeder are similar and will be commented parallel (in the form TDK/Fluxtrol A impeder). The average values of $22.44 \mathrm{HRC} / 22.14 \mathrm{HRC}$ (aberration of the local measured value in both cases is up to $5 \%$ ) in the weld and 10.76 HRC/9.24 HRC (aberration up to $24 \%$ ) outside the weld were obtained. A significant difference between hardness in the weld area and outside the weld is evident. The change of hardness on the circumference of the pipe is given in Fig. 4.

The hardness changes intensively and is far away from the ideal constant value over the circumference of a pipe. The demand for a constant quality of the steel pipe material over the whole section arises from the requirements in further tube processing. The seamless pipes are of the highest quality, and they meet these demands, but their price is much higher. Therefore, there is a strong need to improve the quality of seamed pipes and to spread the range of application where they represent an optimal technical-economic solution.

In the improvement of the quality, the natural step is to investigate the reasons for variable hardness. The structure of the material is to be investigated. Ideally, constant chemical characteristics and mechanical structure of the pipe should not differ from those of the input steel strip. The change of hardness over the pipe leads to the suspicion that the chemical characteristics of the pipe have changed. These changes were investigated by using an optical quant meter.

\subsection{The testing of chemical structure using an optical quant meter}

The results of the chemical analysis for a steel strip, the weld of the pipe, and the pipe section outside the weld area (for a specimen of diameter $21.3 \mathrm{~mm}$ and of thickness

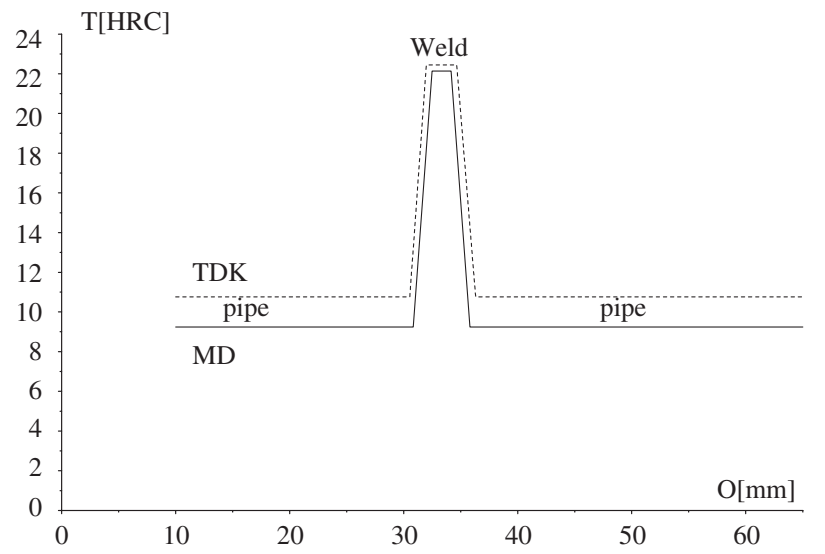

Fig. 4 The change of hardness over the circumference of a pipe.

Table 1 The results of the chemical analysis.

\begin{tabular}{|c|c|c|c|c|c|}
\hline \multirow{3}{*}{$\begin{array}{l}\text { Chemical } \\
\text { element }\end{array}$} & \multicolumn{5}{|c|}{ Chemical composite in [\%] } \\
\hline & \multirow[b]{2}{*}{ Steel strip } & \multicolumn{2}{|c|}{ TDK impeder } & \multicolumn{2}{|c|}{ Fluxtrol A impeder } \\
\hline & & $\begin{array}{l}\text { Pipe inside } \\
\text { the weld }\end{array}$ & $\begin{array}{l}\text { Pipe outside } \\
\text { the weld }\end{array}$ & $\begin{array}{l}\text { Pipe inside } \\
\text { the weld }\end{array}$ & $\begin{array}{l}\text { Pipe outside } \\
\text { the weld }\end{array}$ \\
\hline $\mathrm{C}$ & 0.24766 & 0.96890 & 0.14992 & 0.15942 & 0.24014 \\
\hline $\mathrm{Si}$ & 0.01415 & 1.58527 & 0.00997 & 0.00867 & 0.02123 \\
\hline $\mathrm{S}$ & 0.00938 & 0.01886 & 0.00453 & 0.00030 & 0.01169 \\
\hline $\mathrm{P}$ & 0.00315 & 0.00517 & 0.00018 & 0.00432 & 0.00366 \\
\hline $\mathrm{Mn}$ & 0.46453 & 4.53100 & 0.46852 & 0.43031 & 0.56453 \\
\hline $\mathrm{Ni}$ & 0.00624 & 0.52641 & 0.00649 & 0.01157 & 0.01841 \\
\hline $\mathrm{Cr}$ & 0.01770 & 0.08305 & 0.01718 & 0.01620 & 0.02545 \\
\hline Mo & 0.03550 & 0.47873 & 0.03313 & 0.03157 & 0.04372 \\
\hline $\mathrm{V}$ & 0.02004 & 0.08283 & 0.01213 & 0.00673 & 0.03017 \\
\hline $\mathrm{Cu}$ & 0.01767 & 0.05981 & 0.01763 & 0.02271 & 0.04848 \\
\hline W & 0.01698 & 0.5454 & 0.00516 & 0.00483 & 0.04437 \\
\hline $\mathrm{Ti}$ & 0.00252 & 0.04365 & 0.00077 & 0.00010 & 0.00573 \\
\hline Sn & 0.00067 & 0.02330 & 0.00052 & 0.00021 & 0.00506 \\
\hline Co & 0.00595 & 0.02482 & 0.00367 & 0.00316 & 0.01087 \\
\hline $\mathrm{Al}$ & 0.05359 & 0.81243 & 0.04511 & 0.03432 & 0.06666 \\
\hline $\mathrm{Nb}$ & 0.02114 & 0.24467 & 0.01024 & 0.00691 & 0.04701 \\
\hline $\mathrm{Mg}$ & 0.02877 & 0.09602 & 0.02541 & 0.02413 & 0.03761 \\
\hline $\mathrm{Fe}$ & 99.0594 & 89.9171 & 99.1999 & 99.2347 & 98.8059 \\
\hline
\end{tabular}

$2.65 \mathrm{~mm}$ ) are shown in Table 1.

By the TDK impeder, the chemical structures of the weld and the pipe section outside the weld are significantly different, and both are different from the chemical structure of the incoming steel strip. The content of carbon (C) in the weld of the pipe is almost four times higher than in the incoming strip and it amounts to $0.96 \%$. According with the Ref. 10), the carbon content higher than $0.35 \%$ make the steel tiled, i.e. brittle. Therefore, it is obvious why the welds broke up in the mechanical tests of flattening. The carbon content in the pipe outside the weld is about $40 \%$ lower than that in the strip.

As a rule, the content of the other elements rises in the weld area, and decreases in the pipe material outside the weld. As the consequence, the percentage of iron is lower in the weld than in the incoming strip.

Because of these unexpected results of the chemical analysis of the pipe that is $21.3 \mathrm{~mm}$ in diameter and $2.65 \mathrm{~mm}$ thick, the tests were repeated for the pipe that is $26.9 \mathrm{~mm}$ in diameter and $2.5 \mathrm{~mm}$ thick. Similar, qualitatively the same, 


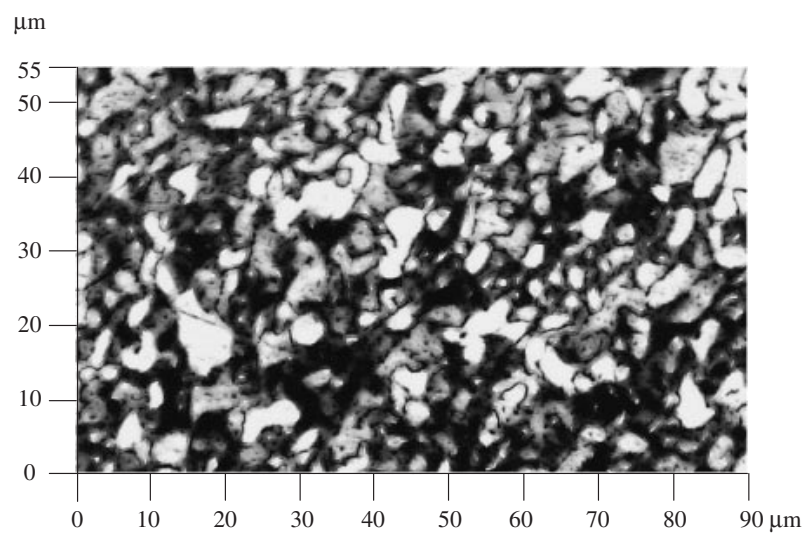

Fig. 5 The metallographic picture of the weld of a steel pipe produced using the TDK impeder.

results were obtained.

The conclusion is that the HF inductive welding of steel pipes with the TDK ferrite impeder leads to the radical deterioration of the chemical structure of the material in pipe weld. The structure of the material does not even meet the standards for the steel in the Refs. 11-13) any more. The last idea of gathering as much as possible information about the occurrences in the weld was to carry on the metallographic analysis.

Opposite to the TDK impeder, Fluxtrol A does not lead to the strong change of a content of carbon. That is the main reason of much better behavior of pipes in mechanical tests produced using the Fluxtrol A impeder than using the TDK impeder.

\subsection{The metallographic analyses}

The analyses were made for the incoming steel strip, for the weld of still pipe and for the basic section of pipe, outside the weld. Both pipes (of diameter $26.9 \mathrm{~mm}$ and thickness $2.5 \mathrm{~mm}$ and of diameter $21.3 \mathrm{~mm}$ and thickness $2.65 \mathrm{~mm}$ ) were investigated.

In the metallographic pictures of the weld produced by TDK-IP1 ferrite impeder, a high content of the carbon between the particles can be seen (Fig. 5) and as particles enlarge structure changes, which causes low mechanical resistance to flattening, i.e. low quality of the pipe.

As shown in Fig. 6, by Fluxtrol A between the particles there is no increase of carbon. The structure is practically identical to the structure of incoming steel strip. This is one more explanation of the good quality of pipes produced using the Fluxtrol A impeder.

\subsection{The recapitulation of the changes in the material}

All three kinds of tests conducted in order to study the causes of the bad characteristics of pipes have shown that the HF inductive welding of steel pipes, using the TDK ferrite impeder, produces irreversible and harmful processes. The changes in chemical and mechanical characteristics of the material in the weld and outside the weld of the final steel pipe in respect to the incoming steel strip occur. The changes are so great, that the material of the pipe does not meet any of the standards.

The authors would not essay an explanation of the causes

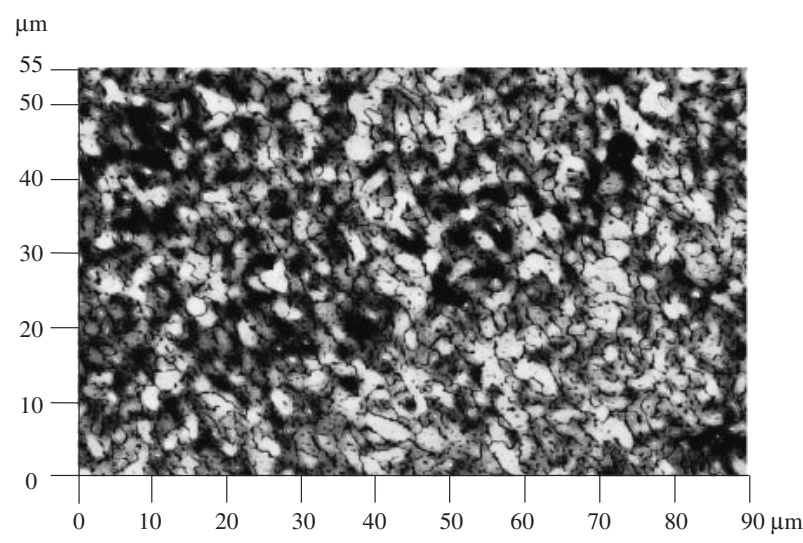

Fig. 6 The metallographic picture of the weld of a steel pipe produced using the Fluxtrol A impeder.

for these occurrences. The exposed occurrences are certainly caused by various factors, and a theoretical explanation can be searched on various ways. One of them is through chemical reactions of the steel material with the ambient air, or with the material of the impeder (it consists of an epoxy tube, in which ferrite is inserted, and which is cooled with a cooling fluid through a plastic hose). The chemical reactions take place under the specific conditions of high temperature, strong magnetic field and steel material movement. The second possible theory is a classical, metallurgical one. The authors have even considered the idea that certain atomic reactions come about with the existing temperature and electromagnetic fields.

Performed test showed the benefits of application of new Fluxtrol A material for impeders regarding the quality of pipes.

\section{Conclusions}

As a result of a long-term comprehensive work of the authors in researching and improving the HF inductive welding of steel pipes, the most significant results in decreasing the power consumption by applying the magneto-dielectric materials for the impeder and in the construction of HF electric generators have been published in the previous papers. Further work, presented in this paper, was focused to the weld quality, as the essential parameter for evaluating a technological line for the HF inductive welding.

The application of new Fluxtrol A material confirmed its superiority to the widely used ferrite impeder. The application of Fluxtrol A impeder results with better performance in standard mechanical flattening and hydrostatic testing of pipes. It means that Fluxtrol A can be strongly recommended as an optimal solution in the production of pipes using the inductive welding.

In order to investigate difference in mechanical characteristics of the pipes produced by TDK and Fluxtrol A impeders, the chemical characteristics and mechanical structure of the material are observed. It turned out that by the TDK impeder the structure of the material of formed pipe in the weld and outside the weld is significantly different from the material of incoming strip.

The physics of the phenomena arising during a weld 
forming with $\mathrm{HF}$ induction heating is of a high complexity. The aim of the authors was to state the practical problem of the weld quality, to point to possible diagnostic techniques and to notice possible theoretical ways to explain the change of the structure of material. A deeper study of the physics is possible topic of the research of the authors and the professionals and scientific public.

\section{REFERENCES}

1) N. A. Shamov, V. I. Lunin and N. V. Ivanov: High frequency metal welding, (Leningrad, Masinostroenie, 1977) pp. 3-198.

2) D. Gulaev: Improvements of production technologies and quality of electrically welded tubes, (Kijev, Tehnika, 1984) pp. 4-116.
3) N. P. Gluhanov and V. N. Bogdanov: Metal welding with high frequency heating, (Leningrad, Mashgiz, 1962) pp. 5-175.

4) K. Mitani and K. H. Shibuya: Impeder: How its innovation and design impacts the welding process. Proc. $8^{\text {th }}$ Annual World Tube Congress. (Chicago, Illinois, USA.) (1992) pp. 25-33.

5) M. S. Milićević and V. M. Milićević: IEE Proceedings, Science, Measurement and Technogy, 149, No. 3, (2002), pp. 113-116.

6) M. S. Milićević and V. M. Milićević: European Transactions on Electrical Power, 14 No. 2 (2004) 111-118.

7) STANDARD DIN-50104, 1947.

8) STANDARD ISO-R202, 1961

9) STANDARD ISO-R80, 1959.

10) H. Schumann: Metallography. (Leipzig, VEB Deutcher Verlag für Grunstoffindustrie, 1989).

11) STANDARD ISO-4019, 1982.

12) STANDARD ISO-3306, 1975.

13) STANDARD EN 10025, 1990 